\title{
Gambaran Kejadian Persalinan Disfungsional pada Pasien Anemia dalam Kehamilan di RSUP Dr. M. Djamil Periode 2010-2012
}

\author{
Mega Redha Putri ${ }^{1}$, Joserizal Serudji ${ }^{2}$, Efrida ${ }^{3}$
}

\begin{abstract}
Abstrak
Persalinan disfungsional (distosia akibat kelainan tenaga) merupakan masalah persalinan dunia dan merupakan salah satu indikasi dilakukannya intervensi selama persalinan dengan tingkat kekerapan kejadian sebesar 4-40\%. Persalinan disfungsional dapat disebabkan oleh anemia dalam kehamilan. Kekuatan kontraksi uterus atau his ibu hamil dengan anemia kurang dari normal, lemah dan dalam durasi yang pendek sehingga tidak cukup kuat untuk melahirkan janin dan ibu hamil akan cepat lelah, akibatnya persalinan dapat mengalami perlambatan atau terhenti. Semakin berat anemia, semakin berat manifestasi klinis yang muncul. Tujuan penelitian ini adalah untuk mengetahui gambaran kejadian persalinan disfungsional pada pasien anemia dalam kehamilan berdasarkan derajat anemia di RSUP Dr. M. Djamil Padang. Ini merupakan penelitian deskriptif menggunakan data retrospektif bagian rekam medik RSUP. Dr. M. Djamil Padang periode 2010-2012. Data yang digunakan sebanyak 61 sampel. Hasil penelitian menunjukkan distribusi kejadian persalinan disfungsional paling tinggi pada anemia derajat ringan yaitu sebanyak 4 orang $(8,7 \%)$, anemia derajat sedang sebanyak 1 orang $(8,3 \%)$ dan anemia derajat berat $0 \%$. Hasil penelitian menunjukkan bahwa derajat anemia dalam kehamilan tidak mempengaruhi angka kejadian persalinan disfungsional.
\end{abstract}

Kata kunci: anemia dalam kehamilan, persalinan disfungsional, distosia, ibu hamil

\section{Abstract}

Dysfunctional labor (dystocia due to abnormal labor) is a worldwide labor problem and one of the indications for intervention during labor with prevalence rate 4-40\%. Dysfunctional labor can be caused by anemia in pregnancy. The strength of uterine contractions or his in pregnant women with anemia is less than normal, weak and short in duration so it is not strong enough to bear the fetus and the pregnant women will get tired, causing a slow or stopped. The more severe anemia, the more severe clinical manifestations appear. The objective of this study was to know the incidence of dysfunctional labor in patients with anemia on pregnancy based on the degree of anemia in Dr. M. Djamil Hospital Padang. This research was a descriptive study using retrospective data from medical record of Dr M. Djamil Hospital Padang on period 2010-2012. The samples used were 61 samples. The results showed the distribution of the high incidence of dysfunctional labor is mild anemia as many as 4 people (8.7\%), on moderate anemia is 1 person (8.3\%) and there is none on the severe degree (0\%). The study shows that the degree of anemia in preganacy doesn't affect the incidence of dysfunctional labor.

Keywords: anemia in pregnancy, dysfunctional labor, dystocia, pregnant woman

Affiliasi penulis: 1. Pendidikan Dokter FK UNAND (Fakultas Kedokteran Universitas Andalas Padang), 2. Bagian IImu Obstetri dan Ginekologi FK UNAND/RSUP Dr. M. Djamil, 3. Bagian Patologi Klinik FK UNAND/RSUP Dr. M. Djamil

Korespondensi: Mega Redha Putri, E-mail : megaredhaputri@yahoo.com, Telp: 082283637590

\section{PENDAHULUAN}

Persalinan disfungsional atau yang lebih dikenal dengan distosia karena kelainan tenaga, merupakan masalah persalinan dunia dan merupakan salah satu indikasi dilakukannya instervensi selama 
persalinan dengan tingkat kekerapan kejadian sebesar 4-40\%. ${ }^{1}$ Di Amerika Serikat, 20-25\% persalinan dilakukan dengan cara bedah sesar, 30\% diantaranya adalah karena distosia. Sebanyak $8-11 \%$ pada persalinan dengan presentasi kepala terjadi kelainan pada kala I. ${ }^{2}$

Setengah juta kematian ibu yang diperkirakan terjadi setiap tahunnya, sebanyak 99\% terjadi di negara berkembang. Persalinan yang sulit atau macet dan berlangsung lama termasuk salah satu dari lima penyebab utama kematian ibu di negara berkembang, walaupun terdapat variasi antara suatu negara dengan negara lainnya. Persalinan yang lama dapat menyebabkan kesulitan melahirkan janin, dehidrasi ibu, perdarahan postpartum, asfiksia janin, infeksi neonatal serta kematian. Dapat dipastikan bahwa distosia dan efek yang menyertainya berkontribusi dalam jumlah kematian ibu dan janin di seluruh dunia. ${ }^{3}$

Distosia didefinisikan sebagai persalinan abnormal akibat kelainan pada power (kontraksi uterus), passeger (posisi, ukuran dan presentasi janin) dan passage (pelvis). ${ }^{4}$ Distosia akibat kelainan tenaga terdiri atas dua tipe pola kontraksi yag berbeda yaitu hypertonic dan hypotonic. Pada penelitian yang dilakukan oleh Knapp dan Warenski pada tahun 1963 pada 71 orang ibu hamil dengan persalinan disfungsional, 70 orang diantaranya adalah tipe hypotonic. $^{5}$

Hypotonic uterine inertia atau inersia uteri hipotonik menyebabkan proses persalinan terhenti dan janin terlantar akibat adanya kelainan his pada rahim ibu, berupa kekuatan yang tidak adekuat untuk melakukan pembukaan mulut rahim atau mendorong janin keluar. Salah satu penyebab kelainan his adalah anemia yang terjadi selama kehamilan. ${ }^{6}$

Anemia dalam kehamilan merupakan suatu hal yang mengancam ibu dan janin karena mengakibatkan persalinan disfungsional, kelahiran prematur, perdarahan, inersia uteri, pertumbuhan janin terganggu, infeksi, sepsis selama persalinan bahkan abortus. ${ }^{7}$

Menurut Gibney et al tahun 2009 terdapat 370 juta perempuan yang menderita anemia karena defisiensi zat besi di negara berkembang, prevalensi rata-rata lebih tinggi pada ibu hamil sebesar $51 \%$ dibandingkan pada perempuan yang tidak hamil sebesar $41 \% .^{8}$ Data Profil Kesehatan Indonesia tahun 2008 menunjukkan bahwa prevalensi anemia pada ibu hamil di Indonesia adalah $70 \%$. Di Sumatera Barat, jumlah ibu hamil yang mengalami anemia sebesar $69 \%{ }^{9}$ Angka prevalensi anemia di Indonesia ini jelas meningkat 57\% dibandingkan prevalensi tahun 2001 yang tercatat sebesar $40,1 \%$ berdasarkan Survei Kesehatan Rumah Tangga tahun 2001. Anemia yang sering ditemukan pada ibu hamil adalah anemia defisiensi besi dengan prevalensi paling tinggi pada sebesar $70 \%$ dibandingkan dengan pekerja yang berpenghasilan rendah (40\%), anak sekolah (30\%) serta pada balita (40\%). ${ }^{10}$ Komplikasi yang paling sering terjadi adalah perdarahan, infeksi, abortus, dan persalinan disfungsional sekitar $90 \%$ yang berimbas pada kematian janin (12-28\%), kematian perinatal (30\%), dan kematian neonatal (7-10\%). Anemia defisiensi besi ini memerlukan perhatian yang serius oleh semua pihak yang terkait dalam pelayanan kesehatan khususnya pelayanan kesehatan di Indonesia. $^{11}$

\section{METODE}

Penelitian ini merupakan penelitian cross sectional dengan metode deskriptif retrospektif. Penelitian dilakukan di Bagian Rekam Medis RSUP Dr. M Djamil Padang dari Februari sampai Maret 2013. Populasi penelitian adalah data rekam medis ibu hamil yang melakukan persalinan di RSUP Dr. M. Djamil Padang selama periode Januari 2010 - Desember 2012. Sampel yang digunakan adalah bagian dari populasi yang memenuhi kriteria inklusi dan kriteria ekslusi yaitu sebanyak 61 sampel. Data yang diperoleh diolah secara manual, kemudian data tersebut ditampilkan dalam bentuk tabel distribusi frekuensi.

\section{HASIL}

Tabel 1. Distribusi frekuensi subjek penelitian menurut umur.

\begin{tabular}{ccc}
\hline Anemia dalam Kehamilan & $\mathbf{F}$ & $\%$ \\
\hline Umur (tahun) : & & \\
$\leq 20$ & 10 & 16,4 \\
$>20-30$ & 31 & 50,8 \\
$>30$ & 20 & 32,8 \\
\hline
\end{tabular}




\begin{tabular}{lll}
\hline Jumlah & 61 & 100
\end{tabular}

Tabel 1 memperlihatkan frekuensi terbanyak pasien anemia dalam kehamilan yang dijadikan sebagai sampel penelitian berada pada kelompok usia 20-30 tahun, yaitu sebanyak 31 kasus (50,8\%) dan frekuensi paling sedikit berada pada kelompok usia kurang dari 20 tahun, yaitu sebanyak 10 kasus $(16,4 \%)$.

Tabel 2. Distribusi frekuensi subjek penelitian menurut jumlah paritas

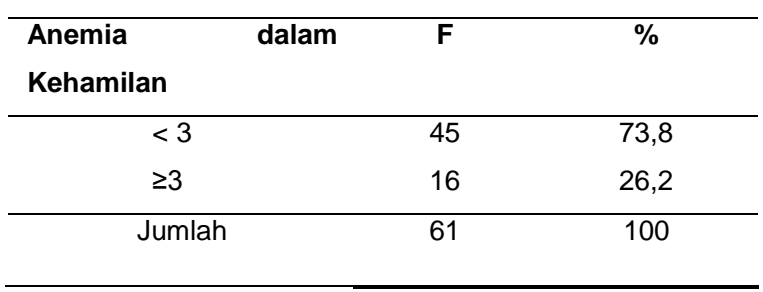

Berdasarkan Tabel 2, dapat dilihat bahwa frekuensi terbanyak pasien anemia dalam kehamilan memiliki paritas kurang dari 3, yaitu 45 orang (73,8\%) dan frekuensi paling sedikit berada pada kelompok dengan jumlah paritas lebih sama dengan 3, yaitu 16 orang $(26,2 \%)$.

Tabel 3. Distribusi frekuensi subjek dengan anemia dalam kehamilan berdasarkan kejadian persalinan disfungsional

\begin{tabular}{|c|c|c|c|c|c|c|}
\hline \multirow{3}{*}{$\begin{array}{c}\text { Derajat } \\
\text { Anemia } \\
\text { dalam } \\
\text { Kehamilan }\end{array}$} & \multicolumn{3}{|c|}{ Persalinan } & Disfungsional & \multicolumn{2}{|c|}{ Total } \\
\hline & \multicolumn{2}{|c|}{ Ya } & \multicolumn{2}{|c|}{ Tidak } & \multirow[b]{2}{*}{$f$} & \multirow[b]{2}{*}{$\%$} \\
\hline & $f$ & $\%$ & $f$ & $\%$ & & \\
\hline $\begin{array}{l}\text { Anemia } \\
\text { Ringan }\end{array}$ & 4 & 8,7 & 42 & 91,3 & 46 & 100 \\
\hline $\begin{array}{l}\text { Anemia } \\
\text { Sedang }\end{array}$ & 1 & 8,3 & 11 & 91,7 & 12 & 100 \\
\hline $\begin{array}{l}\text { Anemia } \\
\text { Berat }\end{array}$ & 0 & 0 & 3 & 100 & 3 & 100 \\
\hline Total & 5 & & 56 & & 61 & \\
\hline
\end{tabular}

Data pada Tabel 3 menggambarkan kejadian persalinan disfungsional paling banyak dialami oleh ibu dengan anemia ringan yakni 4 orang $(8,7 \%)$ lalu diikuti dengan ibu yang menderita anemia sedang yaitu 1 orang $(8,33 \%)$ dan tidak ditemukan kejadian persalinan disfungsional pada anemia berat $(0 \%)$.

\section{PEMBAHASAN}

Pada Tabel 1, diketahui bahwa frekuensi penderita anemia dalam kehamilan paling tinggi adalah pada ibu yang berumur 21-30 tahun yakni $49,2 \%$ atau sebanyak 30 orang. Sementara pada subjek yang berumur kurang dari 20 tahun diketahui menderita anemia sebanyak 10 orang $(16,4 \%)$ dan yang berumur diatas 30 tahun sebanyak 21 orang $(34,4 \%)$. Hasil penelitian ini menunjukkan distribusi frekuensi yang tinggi pada kelompok umur lebih dari 20-30 tahun, diduga akibat jumlah sampel yang sedikit sehingga tidak dapat ditarik kesimpulan yang representatif.

Dalam Tabel 2 dapat diketahui bahwa subjek penelitian yang menderita anemia dalam kehamilan rata-rata memiliki jumlah paritas dibawah tiga dengan jumlah 45 orang $(73,8 \%)$ sementara yang mempunyai paritas dengan jumlah lebih dari tiga sebanyak 16 orang $(26,2 \%)$.

Hasil ini tidak sesuai dengan literatur, bahwa jumlah paritas yang melebihi tiga kali merupakan faktor terjadinya anemia sehingga anemia dalam kehamilan lebih sering terjadi pada kelompok ini. Hal ini disebabkan karena terlalu sering hamil dapat menguras cadangan zat gizi tubuh ibu. ${ }^{12}$

Berdasarkan tabel 3 jumlah kejadian persalinan disfungsional paling tinggi pada anemia dengan derajat ringan dengan persentase $8,7 \%$, diikuti dengan anemia sedang dengan persentase $8,3 \%$ lalu anemia berat dengan persentase $0 \%$ atau tidak ditemukan kejadian persalinan disfungsional.

Secara umum, hal ini sejalan dengan penelitian Knapp dan Warenski pada tahun 1963 yang menyebutkan bahwa 20 orang dari 70 ibu hamil yang mengalami persalinan disfungsional berupa inersia uteri hipotonik mempunyai riwayat anemia selama kehamilan. ${ }^{5}$ Sebuah penelitian dengan desain cross-sectional di sebuah rumah sakit bersalin di Semarang terhadap 63 orang ibu hamil didapatkan hasil bahwa 90,6\% ibu hamil yang menderita anemia pada trimester III mengalami partus lama. ${ }^{13}$ Penelitian terdahulu dan hasil penelitian ini sejalan dengan literature karena adanya hubungan antara anemia dalam kehamilan dengan kejadian persalinan disfungsional dan bahwa anemia dalam kehamilan 
dapat berkomplikasi sebagai persalinan disfungsional akibat tidak adekuatnya his ibu selama persalinan. ${ }^{6}$

Hasil ini tidak sejalan dengan literatur yang mengatakan bahwa semakin berat derajat anemia dalam kehamilan semakin besar frekuensi kejadian persalinan disfungsional, yang disimpulkan dari hubungan tingkat keparahan gejala klinis anemia dalam kehamilan dengan derajat anemia yang diderita oleh ibu, seperti yang ditampilkan pada Tabel 3. ${ }^{14}$

Alasan mengapa hasil penelitian tidak sejalan dengan literatur tersebut tidak dapat diterangkan dengan baik, akan tetapi diduga akibat :

1) Kemajuan persalinan tidak semata-mata tergantung dengan kekuatan uterus terutama dalam kasus persalinan disfungsional. ${ }^{15,16}$ Terdapat faktor-faktor lain yang berupa tahanan dalam persalinan seperti pembukaan dan penurunan janin. Tahanan-tahanan ini berbeda-beda per individu, walaupun pembukaan pada multipara lebih mudah dibandingkan dengan nullipara. Walaupun ini adalah hal yang penting tetapi pengelompokkan kekuatan uterus pada saat ini tidak cukup membantu dalam pengelolaan persalinan karena kualitas dan kuantitas kekuatan kontraksi di persalinan yang normal dapat juga terlihat pada persalinan abnormal pada pasien yang berbeda. ${ }^{17}$

2) Penggunaan oksitosin dalam persalinan. Oksitosin diberikan dengan tujuan meningkatkan kontraksi uterus setiap 3-5 menit. Penuntun utamanya adalah jika persalinan sudah masuk fase aktif dan pembukaan yang terjadi kurang dari $1 \mathrm{~cm}$ per jam serta harus dipastikan bahwa tidak ada fetal distress. ${ }^{18}$ Pada persalinan dengan tipe hipotonik, kontraksi uterus ritmis tetapi lemah atau jarang atau keduanya sehingga oksitosin memberikan efek yang baik dalam peningkatan kekuatan dan frekeunsi his. Berdasarkan epidemiologi, tipe ini pun lebih sering terjadi dibandingkan dengan hipertonik dan lebih responsif dengan pemberian oksitosin. ${ }^{17}$

3) Jumlah kejadian anemia berat dan kejadian persalinan disfungsional yang sedikit sehingga tidak representatif.

\section{KESIMPULAN}

Angka kejadian persalinan disfungsional pada pasien anemia derajat ringan dalam kehamilan sebanyak 4 kasus dari 61 kasus.

Angka kejadian persalinan disfungsional pada pasien anemia derajat sedang dalam kehamilan adalah sebanyak 1 kasus dari 61 kasus.

Angka kejadian persalinan disfungsional pada pasien anemia derajat berat dalam kehamilan adalah sebanyak 0 kasus dari 61 kasus.

\section{UCAPAN TERIMA KASIH}

Ucapan terima kasih kepada Dr. dr. Joserizal Serudji, Sp.OG(K) dan dr. Efrida. SpPK. M.Kes atas bimbingan, nasehat dan bantuannya dalam penelitian ini.

\section{DAFTAR PUSTAKA}

1. Neilson JP, Lavender T, Quenby S, Wray S. Obstructed labour. Br Med Bull. 2003; 67:191-204

2. Joy S. Abnormal labor. [serial online] 2011 (diunduh 10 Februari 2013). Tersedia dari: URL: HYPERLINK http://emedicine.medscape.com/ article/273053-overview

3. World Health Organization. Worldwide prevalence of anemia 1993-2005 : WHO Global Database on Anemia. Switzerland: WHO Library Cataloguing-inPublication Data; 2008.

4. Cunningham GF, Leveno K, Bloom S, Hauth J, Rouse D, Spong C. Obstetri William (terj.). Edisi ke 23. Jakarta: EGC; 2009.

5. Knapp RC, Warenski JC. Clinical evaluation of dysfunctional labor. Obstet Gynecol. 1963; 21(5).

6. Mansjoer A. Kapita selekta kedokteran (Jilid I). Jakarta: Media Aesculapius FK Universitas Indonesia; 1991.

7. Kalaivani K. Prevalence and consequences of anemia in pregnancy. Indian J Med Res. 2009;130: 627-33.

8. Gibney MJ, Margetts BM, Kearney JM, Arab L. Gizi kesehatan masyarakat. Jakarta: EGC; 2009.

9. Dinas Kesehatan Kota Padang. Laporan tahunan 2010. Padang; 2011 
10. Supariasa IDN. Penilaian status gizi. Jakarta: EGC; 2002.

11. Manuaba IBG. IImu kebidanan, penyakit kandungan dan keluarga berencana untuk pendidikan bidan. Jakarta: EGC; 2010.

12. Arisman. Gizi dalam daur kehidupan. Buku Ajar IImu Gizi. Jakarta: EGC; 2004.

13. Rini PW. Hubungan antara anemia ibu hamil trimester iii dengan persalinan lama di rumah bersalin Bhakti Ibu Semarang. [serial online] 2010 (diunduh 10 Februari 2013). Tersedia dari: URL: HYPERLINK http://eprints.undip.ac.id/35190/1/ 3793.pdf

14. Irawan C. Penyakit-penyakit pada kehamilan: peran seorang internis. Jakarta: Pusat Penerbitan Ilmu Penyakit Dalam FK Universitas Indonesia; 2008.
15. Seitchik J, Chatkoff ML. Intrauterine pressure wave form characteristics in hypocontractile labor before and after oxytocin administration. Am J Obstet Gynecol. 1975;123(4):426-34.

16. SteerPJ, Carter MC, Beard RW. Normal levels of active contraction area in spontaneus labour. $\mathrm{Br} J$ Obstet Gynaecol. 1984;91:211-9.

17. Drennan KJ, Blackwell S, Sokol R. Abnormal labor : diagnosis and management. [serial online] 2008 (diunduh 10 Februari 2013). Tersedia dari: URL: HYPERLINK http://www.glowm.com/?p=glowm. $\underline{\mathrm{cml} / \text { sectionview\&articleid }=132}$

18. O'Discroll K, Meager D, MacDonald D, Geoghegan F. Traumatic intracranial haemorrhage in firstborn infants and delivery with obstetric forceps. British J Obs Gyn. 1981;85:577-81. 